\title{
Somaclones of Cereus peruvianus Mill. (Cactaceae) with High Morphological Divergence May Generate New Varieties of Ornamental Cacti and Provide Relevant Chemical Compounds
}

Paula Garcia Martin ${ }^{1}$, Juliana Sala de Faria Tavares ${ }^{1}$, Claudete Aparecida Mangolin ${ }^{2}$, and Maria de Fátima P. S. Machado ${ }^{2 *}$

${ }^{1}$ Postgraduate Program in Genetics and Breeding; ${ }^{2}$ Department of Biotechnology Genetics and Cellular Biology, State University of Maringá, 87020-900 Maringá PR Brazil.

*Corresponding author: Maria de Fátima Pires da Silva Machado- Department of Biotechnology Genetics and Cell Biology, State University of Maringá, 87020-900 Maringá PR Brazil; Fax +55 4430114681-mfpsmachado@uem.br

\begin{abstract}
Somaclones with typical and atypical shoots were regenerated from a callus culture in the same culture medium and in equal culture conditions. Since the genetic relationship among regenerated somaclones has not been investigated, current study employed heterologous microsatellite primers to examine the molecular diversity within and among somaclones, showing typical and atypical phenotypes with high morphological divergence. Nei identity value calculated between the somaclones was high $(I=0.929)$ and AMOVA showed higher genetic variation within (96\%) than among (4\%) the samples of somaclones. The polymorphism in the microsatellite loci indicated high levels of mean observed and expected heterozygosity in atypical somaclones, presumably with high adaptive potential and as source of genotypes for generation of new varieties of ornamental cacti. Low molecular divergence between typical and atypical morphologies of somaclones is a promising perspective for use of the atypical somaclones as source of chemical compounds of commercial and industrial interest. The somaclonal variations occurring in vitro callus culture has generated phenotypically differentiated subpopulations with low molecular divergence, however with high genetic variability, enough to be recommended as a source of genotypes to generate new varieties of ornamental cacti and of plants with new traits, necessary for breeding programs.
\end{abstract}

Keywords: somaclones, micropropagation, cactus, Cactaceae, microsatellite transferability, genetic diversity 


\section{Introduction}

Cacti are appreciated as ornamental plants due to their beautiful flowers and particularly to their great variety and diversity. Pérez-Molphe-Balch et al. [11] report tissue culture techniques in more than a hundred species from more than 40 genera of ornamental cacti with high demand in the international trade market. Barrel-shaped cacti are most frequently used as ornamental plants [2], while column-shaped cacti are frequently employed to embellish home gardens and public parks. However, private collectors form a specialized market that is primarily interested in rare or newly discovered species within the Cactaceae family, with high commercial value.

Somaclones of columnar cactus Cereus peruvianus, regenerated from callus tissues, showed somaclonal variations at morphological and molecular level $[3,4]$ and may be characterized as rare unique copies. Somaclonal variations, frequently evident in regenerated plants from in vitro callus culture [5], may be used to obtain new varieties of ornamental interest. Further, industrial and economic importance has been attributed to $C$. peruvianus cultivated in southern Brazil. C. peruvianus plants have been used as sources of chemical compounds for the cosmetic, food and pharmaceutical industries [69]. In vitro callus culture has been a fast and efficient method to obtain several regenerated plants [3].

The following morphologies were observed in 20-year-old somaclones: $i$ ) typical or regular shoots (erect, with linear ribs) resembling those found in C. peruvianus plants growing from seeds in cultivated populations $(62.5 \%)$; ii) atypical shoots, in which the areoles lie in broken ribs (with the formation of knobs, spaced regularly or irregularly), sometimes with tortuous areoles resembling spiraled ribs (23\%); and iii) mixed shoots $(14.5 \%)$ showing mixed morphological forms (typical and atypical parts). Molecular markers (randomly amplified DNA-polymorphism and isozymes) were used to examine relationships between somaclones and $C$. peruvianus plants grown from seeds in cultivated populations $[10,11]$. However, the genetic relationship between regenerated somaclones from callus culture, with typical and atypical phenotypes, has yet to be investigated. Callus culture was induced from typical plants (obtained from seeds) and typical and atypical somaclones regenerated from calluses (in the same culture medium and conditions) represent morphologically divergent subpopulations.

As morphological divergence between typical and atypical somaclones is evident, our hypothesis is that the typical and atypical somaclones represent two clonal subpopulations genetically divergent at molecular level, and also that the atypical somaclones have higher molecular diversity than the typical ones. Current study employed heterologous microsatellite primers to examine the molecular diversity within and among somaclones, showing typical and atypical phenotypes. Microsatellites are simple sequence repeats (SSR) occurring in tandem and abundantly distributed in coding or non-coding regions of plant genomes [12]. Several studies have shown the possibility of microsatellite transferability in Cactaceae [13-16]. Consequently, heterologous microsatellite primers were employed to assess the diversity and divergence between the typical and atypical somaclones at molecular level. High levels of molecular diversity in atypical somaclones may provide an opportunity to generate morphological variants to improve ornamental cacti. In contrast, low molecular divergence between typical and atypical somaclones may be a preliminary evidence for major investments in atypical somaclones to obtain the usually chemical compounds (gum, cellulose, hetero-polysaccharide complexes, fatty acids, alkaloids) obtained from plants with typical morphology. 


\section{Materials and methods}

Somaclones were regenerated from induced callus culture using MS medium containing B5 vitamins, $0.8 \%$ agar, 3\% sucrose, and a combination of growth regulators 2,4dichlorophenoxyacetic acid (2,4-D) and $\mathrm{N}$-(2-furanylmethyl)-1H-purine-6 amine (kinetin) according to the method of Oliveira et al. [3]. Callus tissue was formed from hypocotyl stalks of seedlings of $C$. peruvianus, which grew from seeds collected from a single adult plant with typical shoot established at the Iguatemi Experimental Farm of the State University of Maringá. Callus subcultures were performed at 15-day intervals, and 18-20 weeks after culture initiation (total of 23 somaclonal generations) the friable calluses produced cactus shoots (somaclones). Seedlings (somaclones) with typical (areoles in erect ribs) and atypical (areoles in broken ribs forming alternate knobby) shoots were simultaneously regenerated from each callus. Each callus produced 10-50 seedlings (typical and atypical) which were removed from the callus and individualized after the root formation. After acclimatization and growing of the seedlings in to pots containing a mix of red earth (Paleudult) and river sand (1:1) at controlled conditions of laboratory (24 months) the somaclones were transferred and planted at the Experimental Botanic Garden of the State of University of Maringá (Maringá PR Brazil; altitude $554.9 \mathrm{~m} ; 2^{\circ} 25^{\prime} \mathrm{S} ; 51^{\circ}$ $\left.25^{\prime} \mathrm{W}\right)$, where they are maintained as a cultured population with about one hundred plants where have been maintained since 1997 (20 years).

Genomic DNA was extracted from shoots of seventeen somaclones showing typical shoot morphologies and seventeen somaclones showing atypical shoot morphologies (Figure 1). Pieces of shoots of each typical and atypical somaclones were cut in random parts of the shoots. DNA was extracted from $200 \mathrm{mg}$ of shoots using the methodology described by Resende et al. [10]. After DNA extraction, DNA quantity and quality were determined by $0.8 \%$ agarose gel electrophoresis buffered with $1 \mathrm{X}$ TAE (0.04 M Tris-Acetate and 0.001 M EDTA). A standard DNA ladder ( $\lambda$ phage, 50, 100 and $150 \mathrm{ng}$ ) was used as a marker. The gel was stained with $0.5 \mu \mathrm{g} \cdot \mathrm{mL}^{-1}$ ethidium bromide, and the image was visualized with a Molecular Image LoCCUS L-PIX - HE (LOCCUS DO BRASIL LTDA., São Paulo, SP., Brazil) using the Picasa 3 software.

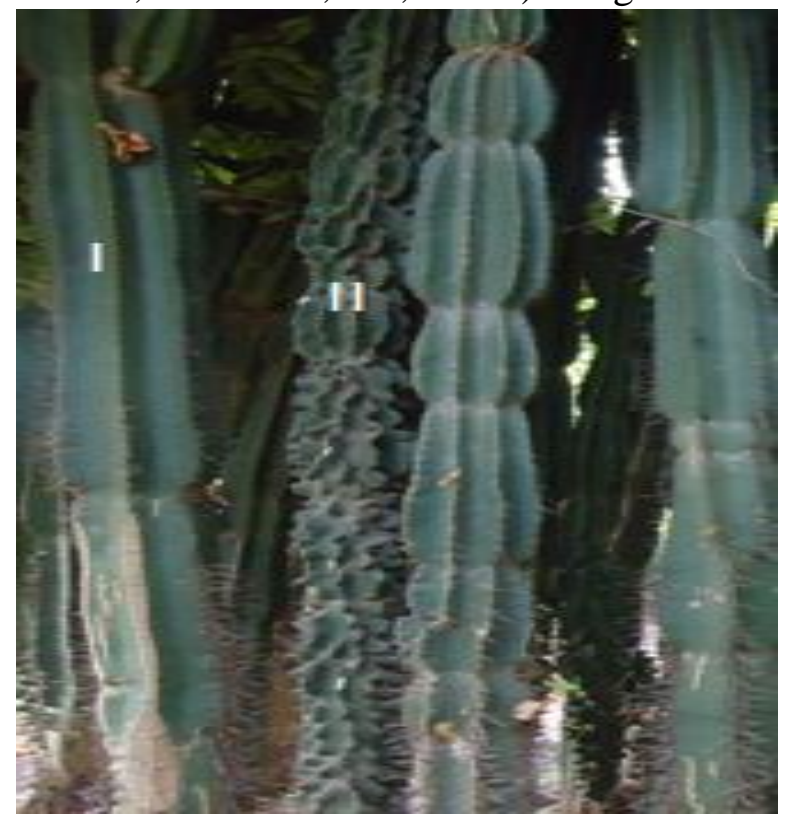


Figure 1. Somaclones of Cereus peruvianus maintained at the Experimental Botanic Garden of the State University of Maringa showing typical (I) and atypical (II) shoot morphologies.

The microsatellite primer transferability was analyzed by testing a total of 33 primer pairs from Polaskia chichipe (seven primer pairs), Astrophytum asterias (six primer pairs), Ariocarpus bravoanus (eight primer pairs), and Echinocactus grusonii (twelve primer pairs). The polymerase chain reaction (PCR) was performed using 0.2 $\mathrm{mL}$ microtubes in a Techne TC-512 thermocycler. A $20 \mu \mathrm{L}$ reaction was carried out using $20 \mathrm{ng}$ of genomic DNA, $2.0 \mu \mathrm{L}$ of $1 \mathrm{X}$ buffer containing Tris- $\mathrm{HCl}$ (10 mM Tris$\mathrm{HCl} \mathrm{pH} 8.3$ and $50 \mathrm{mM} \mathrm{KCl}$ ), $2.5 \mathrm{mM}$ of $\mathrm{MgCl}_{2}, 0.1 \mu \mathrm{M}$ dNTPs, $1 \mathrm{U}$ of Taq-DNA Polymerase (Invitrogen), $0.5 \mu \mathrm{M}$ of each of the forward and reverse primers, and Milli$\mathrm{Q}$ water to make up to $20 \mu \mathrm{L}$. Microsatellite amplification was initially performed by Touchdown PCR [17]. The products that were not clearly amplified by Touchdown PCR were amplified again with the program described by Albert and Schmitz [18], and the annealing temperature was changed to between $50-59{ }^{\circ} \mathrm{C}$ to achieve clearer products. Electrophoresis was performed in a 4\% Metaphor agarose gel using 0.5X TBE buffer $(0.45 \mathrm{M}$ Tris-borate and $0.001 \mathrm{M}$ EDTA) at $60 \mathrm{~V}$ for 4 hours. Thereafter, the gels were stained with ethidium bromide at $0.5 \mu \mathrm{g} \cdot \mathrm{mL}^{-1}$, and the image was captured with a Molecular Image LocCUS L-PIX - HE using the Picasa 3 software. The sizes of the fragments were determined using a 100 bp DNA Ladder (Invitrogen). The alleles were confirmed on polyacrylamide gel. The denaturing polyacrylamide gel was prepared at $12 \%$ with $8 \mathrm{M}$ urea. After polymerization, the gel was placed in a vat containing $1 \mathrm{X}$ TBE buffer for vertical electrophoresis, and a pre-run was performed for 30 minutes at 200 volts. After the pre-run, samples were applied to wells. Samples were prepared by combining $10 \mu \mathrm{L}$ of a sample buffer containing formamide and $7 \mu \mathrm{L}$ of the amplified product. The sample buffer was prepared with $900 \mu \mathrm{L}$ bromophenol blue, $900 \mu \mathrm{L}$ xylenecyanol, $900 \mu \mathrm{L}$ TBE (10X), $4.5 \mathrm{~mL}$ Ficol 30\% (diluted in distilled water), $1.8 \mathrm{~mL}$ EDTA $0.5 \mathrm{M} \mathrm{pH} 8.0$ and $3.6 \mathrm{~g}$ sucrose. All components were mixed until the sucrose completely dissolved, and then, 3 volumes of formamide were added (formamide loading buffer ratio is 1:3). Migration was maintained at 200 volts until xylenecyanol run off was obtained from the gel. The polyacrylamide gel was stained with Sybr gold and viewed using the same system used for agarose gels.

The relation between the number of primers showing amplified products and total number of tested primers was used to estimate microsatellite transferability. For analysis of the relationship between the two types of somaclones at molecular level, typical and atypical somaclones were admitted as being two clonal subpopulations of species. The polymorphic microsatellite loci in the typical and atypical somaclones were used to estimate the average number of alleles per locus, the average observed heterozygosity $\left(\mathrm{H}_{\mathrm{o}}\right)$, the expected heterozygosity $\left(\mathrm{H}_{\mathrm{e}}\right)$ and the genetic divergence between the somaclones $\left(\mathrm{F}_{\mathrm{ST}}\right)$ were estimated using the GenAlEx 6.2 software [19]. For exploring the hierarchical partitioning of genetic variation within and between the samples of somaclones we performed an Analysis of Molecular Variance (AMOVA, GenAlEx 6.2) [19].

\section{Results and discussion}

Genomic DNA quantification indicated that the amount of DNA ranged from 5 to 80 $\mathrm{ng} \cdot \mu \mathrm{L}^{-1}$. Nine microsatellite primers from the amplified DNA fragments of Polaskia 
chichipe (Pchi21, Pchi47, Pchi54), Ariocarpus bravoanus (mAbR28, mAbR42, mAbR77) and Echinocactus grusonii (mEgR02, mEgR76 and mEgR78) were polymorphic in the Cereus peruvianus somaclones (Table 1). The six primers from Astrophytum asterias showed no clear SSR-amplifiable products. The global microsatellite transferability was $27.27 \%$ (9 primers showed amplified products / total of 33 primers tested).

Four alleles were observed at the $m A b R 28$ locus, three alleles were observed at the Pchi47, $m E g R 02$, and $m E g R 78$ loci and two alleles were detected at Pchi21, Pchi54, $m A b R 42, m A b R 77$, and $m E g R 76$ loci (Table 2). A total of 23 alleles, which sets an average of 2.56 alleles per locus, were detected in $C$. peruvianus somaclones. The number of alleles in each microsatellite loci was confirmed by electrophoresis in 
Table 1. Nucleotide sequences of the microsatellite primers, simple sequence repeats of each primer, microsatellite transferability from each cactus specie, number of alleles $(\mathrm{Na})$ detected by each primer in the original specie of cactus, number of alleles detected by each primer in the Cereus peruvianus somaclones, variation in allele size (bp) detected in the somaclones.

\begin{tabular}{|c|c|c|c|c|c|c|}
\hline Species & Primer & Nucleotide Sequence & Simple Sequence Repeated & Transferability & $\mathrm{Na}$ & Base Pair \\
\hline Polaskia chichipe & Pchi21 & $\begin{array}{l}\text { CGTTTAGCCCCTCTTTCTCC }^{(\mathrm{F})} \\
\text { GTTCCCAACTGACCGACAAC }^{(\mathrm{R})}\end{array}$ & $(\mathrm{CT})_{5}(\mathrm{AT})_{3}(\mathrm{GT})_{8} \mathrm{GA}(\mathrm{GT})_{5}$ & & 2 & $>100 \mathrm{bp}$ \\
\hline \multirow[t]{2}{*}{ Otero-Arnaiz et al. (2004) } & Pchi47 & $\begin{array}{l}\text { GTCCTTGTGGCTAGCCCTTT }^{(\mathrm{F})} \\
\text { CCATTTCTCTCGCCATCTG }^{(\mathrm{R})}\end{array}$ & $(\mathrm{TG})_{15}$ & & 3 & $136-172 \mathrm{bp}$ \\
\hline & Pchi54 & $\begin{array}{l}\text { CCTTGAGCTTTGACATTGAGA }^{(\mathrm{F})} \\
\text { GGAAGGTTTTCATTGGATGAG }^{(\mathrm{R})}\end{array}$ & $(\mathrm{CA})_{5} \mathrm{CG}(\mathrm{CA})_{5} \mathrm{TG}(\mathrm{CA})_{22}(\mathrm{TA})_{3}$ & $42.86 \%$ & 2 & $446-464 \mathrm{bp}$ \\
\hline Ariocarpus bravoanus & mAbR28 & $\begin{array}{l}\text { CCATAAGCTGTGGTGGGTCT }^{(\mathrm{F})} \\
\text { ATTTTAAAGCTCCCCCTCCA }^{(\mathrm{R})}\end{array}$ & $(\mathrm{AG})_{7}$ & & 4 & $103-176$ bp \\
\hline \multirow[t]{3}{*}{ Hughes et al. (2008) } & $\mathrm{mAbR} 42$ & $\begin{array}{l}\text { GGGCAATTCACTATGCACAA }^{(\mathrm{F})} \\
\text { TTGTCCCACCTTCCCTATTG }^{(\mathrm{R})}\end{array}$ & $(\mathrm{TC})_{10}$ & & 2 & $469-484$ bp \\
\hline & mAbR77 & $\begin{array}{l}\text { CGGGGAAGGAATAATCCAAG }^{(\mathrm{F})} \\
\text { ATGTGCCGTTTGCAATCTTT }^{(\mathrm{R})}\end{array}$ & $(\mathrm{AG})_{4} \mathrm{CG}(\mathrm{AG})_{11}$ & & 2 & $355-371 \mathrm{bp}$ \\
\hline & & & \multicolumn{4}{|c|}{$37.5 \%$} \\
\hline Echinocactus grusonii & mEgR02 & $\begin{array}{l}\text { TGGGTTGGAGAAGTGGAAG }^{(\mathrm{F})} \\
\text { CGGTGTGAGGCTTCATTTG }^{\mathrm{R})}\end{array}$ & $(\mathrm{AG})_{10} \mathrm{AC}(\mathrm{AG})_{2} \mathrm{AC}(\mathrm{AG})_{7}$ & & 3 & $>100 \mathrm{bp}$ \\
\hline \multirow[t]{3}{*}{ Hardesty et al. (2008) } & $\operatorname{mEgR76}$ & $\begin{array}{l}\text { TCACAATTTGGAAGGAAGCA }^{(\mathrm{F})} \\
\text { GTGAGCAAAGGGCTGATTTC }^{(\mathrm{R})}\end{array}$ & $(\mathrm{AG})_{10}(\mathrm{AAG})_{2} \mathrm{C}(\mathrm{CA})_{2}$ & & 2 & $368-395 \mathrm{bp}$ \\
\hline & $\mathrm{mEgR78}$ & $\begin{array}{l}\text { AGCCCAAAGCCCAACTTATT }^{(\mathrm{F})} \\
\text { TGCATGCAATCATAAGGTTTTC }^{(\mathrm{R})}\end{array}$ & $(\mathrm{AG})_{13} \mathrm{GAG}(\mathrm{CA})_{3}$ & & 3 & $250-288 \mathrm{bp}$ \\
\hline & & & \multicolumn{4}{|c|}{$25 \%$} \\
\hline Total & & & & $27.27 \%$ & 23 & \\
\hline
\end{tabular}


polyacrylamide gel. The two variant alleles in agarose gel electrophoresis may migrate at the same gel position and consequently determine homozygote phenotypes. Thus, the use of polyacrylamide gel electrophoresis for analyzing somaclone shoots has actually been important in the identification of the heterozygote phenotypes and number of alleles. The number of alleles per locus on polyacrylamide gel was equal to the number of alleles per locus on agarose gel.

The polymorphisms in the Pchi21, Pchi47, Pchi54, mAbR28, mAbR42, mAbR77, $m E g R 02, m E g R 76$, and $m E g R 78$ loci was $100 \%$ in the plants with atypical and typical phenotypes. However, a smaller number of alleles and lower value of $H_{e}$ in the microsatellite loci detected in the somaclones showing atypical shoots contrary our hypothesis that the atypical somaclones have higher molecular diversity than the typical somaclones. The number of alleles and effective number of alleles was lower in plants with atypical than in plants with typical morphologies (Table 2). The $m E g R O 2^{l}$ allele was not found in somaclones with atypical shoots. The mean expected heterozygosity in plants with the atypical morphologies was also lower $\left(\mathrm{H}_{\mathrm{e}}=0.452\right)$ than the $\mathrm{H}_{\mathrm{e}}$ detected in plants with the typical morphologies $\left(\mathrm{H}_{\mathrm{e}}=0.501\right)$. The value for mean expected heterozygosity $\left(\mathrm{H}_{\mathrm{e}}=0.477\right)$ of both types of somaclones (typical and atypical phenotypes) is near the value for $\mathrm{H}_{\mathrm{e}}$ reported by Sala et al. [11] in loci for esterase isozymes (0.497) for descendants (R1 generation) of the somaclones. Supposedly, in vitro culture would decrease the ability of populations to adapt to abiotic and biotic environmental changes as well as reducing their flexibility in response to pathogens and herbivores [20]. However, genetic diversity was $20 \%$ higher in regenerated somaclones in vitro than in plants cultured in vivo [10] and the somaclones showed higher values of heterozygosity than $C$. peruvianus plants grown from seeds in nature. Lower values of $\mathrm{H}_{\mathrm{e}}$ have been detected in 12 microsatellite loci $\left(\mathrm{H}_{\mathrm{e}}=0.4012\right)$ in 40 cultivated plants of $C$. peruvianus growing from seeds (unpublished results). The high heterozygosity detected in the somaclones (typical: $\mathrm{H}_{\mathrm{e}}=0.501$ and atypical: $\mathrm{H}_{\mathrm{e}}=0.452$ ) may be an important indicator that this plant population as well as their descendants has a substantial amount of genetic variation to adapt to abiotic and biotic environmental changes.

Table 2. Number of somaclones $(\mathrm{N})$, number of alleles $(\mathrm{Na})$ and number of effective alleles $(\mathrm{Ne})$ per polymorphic microsatellite locus, mean heterozygosity observed $\left(\mathrm{H}_{\mathrm{o}}\right)$ and expected $\left(\mathrm{H}_{\mathrm{e}}\right)$ in somaclones of Cereus peruvianus showing typical and atypical shoot morphologies.

\begin{tabular}{lcccccc}
\hline Somaclone & $\mathrm{N}$ & $\mathrm{Na}$ & $\mathrm{Ne}$ & $\mathrm{Ho}$ & $\mathrm{He}$ & $\mathrm{P}(\%)$ \\
\hline Typical & 17 & 2.556 & 2.152 & 0.335 & 0.501 & 100 \\
Atypical & 17 & 2.444 & 1.953 & 0.368 & 0.452 & 100 \\
\hline Total/Mean & 34 & 2.5 & 2.052 & 0.352 & 0.477 & 100 \\
\hline
\end{tabular}

High heterozygosity in somaclones is also important because they may be target of selection processes for generation of new varieties. Different genotypes ("monstruosus", crested, and variegated forms) have been selected in ornamental breeding programs of Cereus [21]. These characteristics are more likely to occur from crossing certain clones. Some crossings have resulted in 100\% "monstruosus" offspring. Thus, atypical somaclones with high heterozygosity represent promising genotypes to the Cereus ornamental plant breeding programs. The potential of the atypical somaclones for generate different "monstruosus" phenotypes (new morphological varieties) is evident in atypical somaclones kept in vases in home gardens (Figure 2), which are promising as ornamental specimens. 


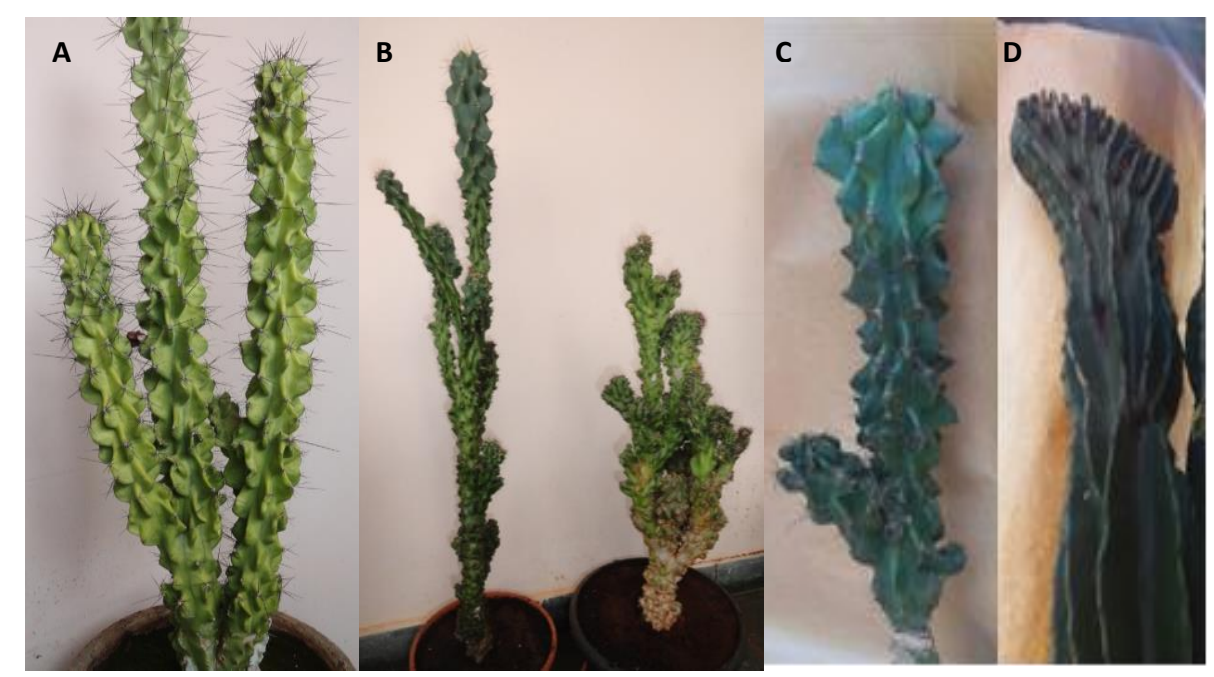

Figure 2. Somaclones of Cereus peruvianus in home gardens showing different "monstruosus" phenotypes (A - D).

Typical and atypical somaclones with high heterozygosity are also promising to broaden the genetic basis of the species. In addition to the ornamental value of this species, several studies have revealed the importance of the $C$. peruvianus species as fruit crop [22 - 24], emphasizing the need to broaden this species's genetic base for breeding programs. The use of in vitro regenerated somaclones in cross-pollination with cultivated plants in vivo may be important as a source for new traits, necessary for breeding programs. Analyses of floral biology and microsporogenesis in somaclones showed that the floral and reproductive characteristics as well as the somaclones' meiotic characteristics are similar to the floral, reproductive, and meiotic characteristics of the $C$. peruvianus natural populations $[25,26]$. Therefore, typical and atypical somaclones may be recommended for crosses with plants grown in vivo to broaden the species's genetic base.

Microsatellites as co-dominant markers revealed the appearance of new alleles results of genetic variation induced in the in vitro culture. Higher number of alleles in microsatellite loci ( $m A b R 28$ and $m E g R 78)$ was also detected in somaclones $\left(\mathrm{N}_{\mathrm{a}}=2.55\right)$ than in the 40 cultivated plants $\left(\mathrm{N}_{\mathrm{a}}=2.33\right)$ (unpublished results). The new alleles were detected in typical and atypical somaclones simultaneity regenerated from callus tissues, and therefore, are no associated with morphological changes in atypical somaclones. The phenotypic changes in plants induced by environmental conditions have been frequently related with epigenetic variations [27]. The DNA methylation events evolved with phenotypic changes were described by Zhang and Hsieh [28] as resulting from epigenetic changes. It is possible that DNA methylation occurring in groups of cells of the callus tissues during the organogenesis may lead to gene silencing in crucial sequences for the most frequent erect pattern for the shoots of the Cereus. Gene silencing occurring in only some groups de cells may explain the origin of the atypical and typical (in absence of gene silencing) somaclones from the same callus. Cells of a callus near medium and far from it often suffer different intensity of environment stresses (medium of culture) and show different variability and unequal division speed. Therefore, it is possible that the responses of the cell groups are spatially variable in a callus. The polymorphism analysis in microsatellite loci of the typical and atypical somaclones was important to show the occurrence of genetic variation in vitro induced 
while the occurrence of epigenetic variations in the atypical somaclones should be investigated further.

Use of heterologous primers to assess molecular divergence in somaclones of $C$. peruvianus also was important to show that the remarkable morphological divergence in vitro induced in the atypical shoots of the somaclones was not followed by differences in the number of repeated units in tandem in the microsatellite loci. The nine microsatellite loci analyzed represent a portion of the genome in the somaclones that are not divergent in the typical and atypical morphologies of the regenerated plants from a callus culture at the same culture medium and equal culture conditions. Thus, until proven otherwise, the premise is that typical and atypical somaclones showing remarkable morphological divergence are examples of two clonal subpopulations with low genetic divergence at molecular level and high morphological divergence $(23 \%$ with atypical shoots and $14.5 \%$ showing mixed morphological forms: typical and atypical). Analyses of the molecular divergence among the somaclones with typical and atypical morphologies indicated a global value lower than $0.05\left(\mathrm{~F}_{\mathrm{ST}}=0.036 \pm 0.018\right)$. According to Wright [29], values of $F_{\mathrm{ST}}$ ranging from 0.01 to 0.05 indicate a minimal difference between populations. The changes in allele frequencies at the nine microsatellite loci were minimal compared to the phenotypic variation observed in the somaclones.

The Nei identity [30] values calculated between the somaclones with different shoot morphologies was high $(\mathrm{I}=0.929)$, indicating less than $8 \%$ of molecular divergence between plants showing typical and atypical shoot morphologies. AMOVA also showed higher genetic variation within $(96 \%)$ than among $(4 \%)$ the samples of somaclones. The minimal molecular divergence observed between the typical and atypical somaclones provides evidence of the common origin of somaclones from callus tissues. The estimated value may represent the molecular diversity (in the nine microsatellite loci) among the morphological types of clones regenerated from the callus culture $(\approx 4 \%)$. While the morphological divergence in the somaclones corresponds to $37.5 \%$ (atypical shoots) the molecular divergence in microsatellite loci was almost 10 times lower. In somaclones de $C$. peruvianus, the somaclonal variation at morphological level is 10 times greater than somaclonal variation at molecular level. Therefore, low molecular divergence between typical and atypical somaclones as well as the high value for Nei's identity $(I=0.929)$ may be preliminary evidences to justify investments for use of atypical somaclones in order to obtain the chemical composts usually obtained from plants with typical morphology. Preliminary studies of hemicelluloses extracted from typical and atypical somaclones (as well as from naturally cultivated plants of $C$. peruvianus) by Fourier Transform Infrared Spectroscopy (FT-IR) showed a similar profile for the FT-IR spectra [31]. Other investments in order to obtain chemical composts such as heteropolysaccharides, fatty acids, and alkaloids, from somaclones with atypical morphology may be recommended due the high molecular similarity between the morphologically divergent plants.

Although microsatellite loci are not necessarily linked to specific coding genes that would lead to the specific morphological changes, the polymorphism at the nine analyzed microsatellites in our study represents genome sequences which can be used as molecular markers to assess changes at DNA level occurring in regenerated plants from the same callus culture. The transferability of microsatellite primers for the Cereus somaclones was a strategy that allowed the estimation of polymorphism and heterozygosity levels as well as relevant information to ornamental cacti breeding programs. The use of the heterologous microsatellite primers in typical and atypical 
somaclones of $C$. peruvianus revealed the callus culture as a source of atypical phenotypes for ornamental cacti breeding programs. Atypical somaclones may be considered of greater ornamental value since one of the aims of the breeding program of ornamental cacti reported by Assis et al. [32] is the selection of suitable genotypes for obtaining variegated plants. The polymorphism in the microsatellite loci indicated: $i$ ) genetic variation at molecular level induced in the callus culture during organogenesis and regeneration of the somaclones; ii) low molecular divergence $(\approx 4 \%)$ for allele frequencies between typical and atypical morphologies of somaclones; iii) a promising perspective for use of the atypical somaclones as source of chemical compounds of commercial and industrial interest; $i v$ ) high levels of mean observed and expected heterozygosity in atypical somaclones, presumably with high adaptive potential and as source of genotypes for generation of new varieties of ornamental cacti.

\section{Conclusion}

The somaclonal variations occurring in vitro callus culture has generated phenotypically differentiated subpopulations with low molecular divergence, however with high genetic variability, enough to be recommended as a source of genotypes to generate new varieties of ornamental cacti and of plants with new traits, necessary for breeding programs.

Acknowledgments: The present study was supported by CAPES (Coordenação de Aperfeiçoamento de Pessoal de Nível Superior, Brasília DF Brazil) (Grant No. 4336/2011-PPG) and CNPq (Conselho Nacional de Desenvolvimento Científico e Tecnológico, Brasília DF Brazil) (Grant No. 306508/2013-3). The authors would like to thank CAPES and CNPq for its financial support.

Author Contributions: Claudete Aparecida Mangolin and Maria de Fátima P. S. Machado conceived and designed the experiments; Paula Garcia Martin and Juliana Sala de Faria Tavares performed the experiments; all authors analyzed the data and Claudete Aparecida Mangolin and Maria de Fátima P. S. Machado wrote the paper.

Conflict of Interest Statement: The authors declare no conflict of interest.

\section{References}

1. Pérez-Molphe-Balch, E.; Santos-Díaz, M.S.; Ramírez-Malagón, R.; Ochoa-Alejo, N. Tissue culture of ornamental cacti. Sci. Agric. 2015, 72, 540-561.

2. Bárcenas, R.T. Commercial trade of Mexican cacti and perspectives for their conservation. Biodiversitas 2006, 68, 11-15.

3. Oliveira, A.S.; Machado, M.F.P.S.; Prioli, A.J.; Mangolin, C.A. In vitro propagation of Cereus peruvianus Mill. (Cactaceae). In Vitro Cell Develop. Biol. Plant 1995, 31, 47-50.

4. Mangolin, C.A.; Prioli, A.J.; Machado, M.F.P.S. Isozyme variability in plants regenerated from calli of Cereus peruvianus (Cactaceae). Biochem. Genet. 1997, 35, 189-204. 
5. Larkin, P.; Scowcroft, W.R. Somaclonal variation - a novel source of variability from cell cultures for plant improvement. Theor. Appl. Genet. 1981, 60, 197-214.

6. Alvarez, M.; Costa, S.C.; Utumi, H.; Huber, A.; Beck, R.; Fontana, J.D. The anionic glycan from the cactus Cereus peruvianus - estrutural features and potential uses. Appl. Biochem. Biotechn. 1992, 34/35, 283-295.

7. Alvarez, M.; Costa, S.C.; Huber, A.; Baron, M.; Fontana, J.D. The cuticle of the cactus Cereus peruvianus as a source of a homo-D-galacturonan. Appl. Biochem. Biotechn. 1995, 51/52, 367-377.

8. Barros, M.J.; Nozaki, J. Pollutants abatement from effluents of paper and pulp industries by flocculation/coagulation and photochemical degradation. Quim. Nova 2002, 25, 736-740.

9. Oliveira, A.J.B.; Machado, M.F.P.S. Alkaloid production by callous tissue cultures of Cereus peruvianus (Cactaceae). Appl. Biochem. Biotechn. 2003, 104, 149-155.

10. Resende, A.G.; Mangolin, C.A.; Machado, M.F.P.S. Somaclonal variation in Cereus peruvianus Mill. (Cactaceae): its potential to generate new varieties and broaden the species's genetic basis. J. Basic Appl. Genet. 2010, 21, 33-42.

11. Sala, J.; Mangolin, C.A.; Franzoni, J.; Machado, M.F.P.S. Esterase polymorphism and the analysis of genetic diversity and structure in cactus populations descended from Cereus peruvianus plants regenerated in vitro. Biochem. Genet. 2011, 49, 270282.

12. Kalia, R.K.; Rai, M.K.; Kalia, S.; Singh, R.; Dhawan, A.K. Microsatellite markers: an overview of the recent progress in plants. Euphytica 2011, 177, 309-334.

13. Otero-Arnaiz, A.; Cruse-Sanders, J.; Casas, A.; Mrick, J.L. Isolation and characterization of microsatellites in the columnar cactus: Polaskia chichipe and cross-species amplification within the Tribe Pachycereeae (Cactaceae). Mol. Ecol. Notes 2004, 4, 265-267.

14. Hardesty, B.D.; Hughes, S.L.; Rodriguez, V.M.; Hawkins, J.A. Characterization of microsatellite loci for the endangered cactus Echinocactus grusonii, and their crossspecies utilization. Mol. Ecol. Res. 2008, 8, 164-167.

15. Caruso, M.; Currò, S.; Las Casas, G.; La Malfa, S.; Gentile, A. Microsatellite markers help to assess genetic diversity among Opuntia ficus indica cultivated genotypes and their relations with related species. Plant Syst. Evol. 2010, 290, 8597.

16. Monteiro, E.R.; Mangolin, C.A.; Neves, A.F.; Orasmo, G.R.; Silva, J.G.M.; Machado, M.F.P.S. Genetic diversity and structure of populations in Pilosocereus gounellei (F.A.C.Weber ex K.Schum.) (Cactaceae) in the Caatinga biome as revealed by heterologous microsatellite primers. Biochem. Syst. Ecol. 2015, 58, 712.

17. Don, R.H.; Cox, P.T.; Wainwright, B.J.; Baker, K.; Mattick, J.S. "Touchdown" PCR to circumvent spurious priming during gene amplification. Nucl. Acids Res. 1991, $19,4008$.

18. Albert, S.; Schmitz, J. Characterization of major royal jelly protein-like DNA sequences in Apis dorsata. J. Apicult. Res. 2002, 41, 75-85. 
19. Peakall, R.; Smouse, P.E. GENALEX 6: genetic analysis in Excel. Population genetic software for teaching and research. Mol. Ecol. Notes 2006, 6, 288-295.

20. Allendorf, F.W.; Luikart, G. Conservation and the genetics of populations. Blackwell Publishing, Malden, 2007, pp. 642.

21. Zappi, D.C.; Taylor, R.N.P.; Machado, M.C. Cactaceae. In: Forzza, R.C.; Baumgratz, F.A.; Bicudo, C.E.M.; Canhos, D.A.L.; Carvalho Jr, A.A.; Costa, A.; Costa, D.P.; Hopkins, M.; Leitman, P.M.; Lohm, A.L.G.; Nic Lu Ghadha, E.; Maia, L.C.; Martinelli, G.; Menezes, M.; Morim, M.P.; Nadruz-Coelho, M.A.; Peixoto, A.L.; Pirani, J.R.; Prado, J.; Queiroz, L.P.; Souza, S.; Souza, V.C.; Stehmann, J.R.; Sylvestre, L.S.; Walter, B.M.T.; Zappi, D.C. (eds). Catálogo de Plantas e Fungos do Brasil. Jardim Botânico do Rio de Janeiro, 2010, 1, 822-832.

22. Nerd, A.; Tel-Zur, N.; Mizrahi, Y. Fruits of vine and columnar cacti. In: Nobel, P.S. (ed). Cacti Biology and Uses. University of California Press Ltd, London, England, 2002, pp.185-197.

23. Weiss, J.; Nerd, A.; Mizrahi, Y. Flowering behavior and pollination requirements in climbing cacti with fruit crop potential. HortScience 1994, 29, 1487-1492.

24. Mizrahi, Y. Cereus peruvianus (Koubo) new cactus fruit for the world. Rev. Brasil. Fruticult. 2014, 36, 68-78.

25. Ruvolo-Takasusuki, M.C.C.; Mangolin, C.A.; Machado, M.F.P.S. Somaclones of Cereus peruvianus Mill. (Cactaceae) may contribute towards the broadening of the species genetic basis. Research J. Bot. 2006, 1, 19-23.

26. Silva, N.; Machado, M.F.P.S.; Mangolin, C.A.; Pagliarini, M.S. Microsporogenesis in somaclones of Cereus peruvianus Mill. (Cactaceae). J. Plant Sci. 2006, 1, 8-13.

27. Hirsch, S.; Baumberger, R.; Grossniklaus, U. Epigenetic variation, inheritance, and selection in plant populations. Cold Spring Harb. Symp. Quant. Biol. 2012, 77, $97-$ 104.

28. Zhang, C.; Hsieh, T-F. Heritable epigenetic variation and its potential applications for crop improvement. Plant Breed. Biotechn. 2013, 1, 307-319.

29. Wright, S. Variability within and among populations. In: Evolution and the genetics of population. University of Chicago Press, Chicago, 1978, pp. 79-103.

30. Nei, M. Identity of genes by descent within and between populations under mutation and migration pressures. Theor. Pop. Biol. 1972, 3, 460-465.

31. Corrêa, A.; Mangolin, C.A.; Machado, M.F.P.S.; Gonçalves, R.A.C.; Oliveira, A.J.B. FT-IR spectroscopy comparison of hemicelluloses extracted from Cereus peruvianus somaclones. Biochemistry for a Better World, Abstract Book. 23rd Congress of the International Union for Biochemistry and Molecular Biology (IUBMB) Foz do Iguaçu, Paraná, Brazil, 2015, p. 257. http://www.sbbq.org.br/iubmb2015/cdrom/index.htm.

32. Assis, J.G.A.; Resende, S.V.; Bellintani, M.C.; Coelho, P.J.A.; Correia, D.; Marchi, M.N.G.; Cruz, M.M.; Nahoum, P.I.V.; Menezes, M.O.T.; Meiado, M.V. Conservação ex situ. In: Silva, S.R.; Zappi, D.; Taylor, N.; Machado, M. (Org.), Plano de ação nacional para a conservação das Cactáceas: série espécies 
ameaçadas. Instituto Chico Mendes de Conservação da Biodiversidade, Icmbio, Brasília, Brasil, 2011, pp. 44-54. 